\title{
FORENSIC RESEARCH AND NEW KNOWLEDGE: ARE THEY REACHING THE TARGET AUDIENCE ${ }^{1}$ IN SRI LANKA ?
}

\section{Induwara Goonerathne}

All sectors in Sri Lanka and abroad emphasise the need and the value of research. The situation regarding forensic disciplines is no different. Universities, ministries of health, governments and others encourage research and publications. Besides, merits of research and publication are grater for the researcher when the work is published in 'high impact factor journals'. High impact journals are usually published by developed countries. There are numerous reasons why most high impact factor journals are from the developed countries. The aim of this article is not to debate on why most high impact factor journals are from the developed countries. Nonetheless, the promotional schemes of all institutes in Sri Lanka recognise publications appear in high impact popular journals at a higher value than others with no regard to the work or its impact to the society. There are many reasons why certain high impact work is not published in high impact journals. This article is not to debate it either. There are times and reasons why high impact work should be published in local journals in local language disregarding the impact factor of the platform in which it is published.

With the above context, this paper attempts to explain that the outcomes of forensic research or new knowledge generated in forensic fields do not transcend to the target audience in Sri Lanka. Further, I argue that, firstly, it is of utmost importance that such forensic research findings and new knowledge should reach the respective target audience in Sri Lanka and secondly that one approach to solving this salient issue would be to publish locally conducted forensic research in local journals such as Sri Lanka Journal of Forensic Medicine Science and Law (SLJFMSL). As it (SLJFMSL) is now an indexed journal and available in print and electronic media as an open access free ejournal to anyone it can be readily accessed by both local and foreign individuals alike.

The sources of information and evidence to substantiate the thesis that the new forensic research does not reach the target audience in Sri Lanka arises from three sources : informal class room discussions I had about the said particular issue with lawyers and judges at their post graduate diploma in forensic medicine and science course conducted by University of Peradeniya, then with post graduate students from the Post graduate Institute of Medicine (PGIM) who attend my classes at the department and finally from the police \& prison officers I meet in their regular in house training workshops.

The lawyers and judges do not seem to retrieve scientific articles from foreign data bases. None of the lawyers in the class had

\footnotetext{
${ }^{1}$ What I mean by target audience here include but not limited to judges, lawyers, forensic practitioners, researchers, suspects of crimes, victims, prison officers etc.
} 
access to full papers from any accepted data bases. However, they claimed that they peruse Sri Lanka Journal of Forensic Medicine Science and Law as it is freely available online and that it seems more relevant and acceptable to them as it addresses local or regional forensic issues mainly. Further, the lawyers claimed that they read text books of forensic medicine, but the copies they have are out dated. None of the post graduates from the PGIM trainees even had access to full papers from high impact online relevant journals. As most journals have a subscription fee, many refrain from subscribing due to financial constraints. The HINARI access provided through university does not cover all important forensic articles therefore both post graduates from health ministry and university researchers suffer alike. The police and prison officers do not seem to access forensic journals. They claim they have a language difficulty to understand English. The respective departments neither have provided sufficient support for them to upgrade their English knowledge, nor have they attempted to translate forensic studies to suit the language needs. Neither the department of Police nor the prison department have provided access to any forensic or criminal journal data bases. University academics and forensic researchers find it difficult to retrieve full articles of current interest as most are not retrievable even via hinari which is available for some. I have enquired from a few victims and suspects of criminal cases during my routine interactions with them in regard to their accessibility to scientific information, for which they have said they do not have any access.

This discussion provides ample evidence to construe that forensic research findings and the new knowledge generated does not reach the target audience in Sri Lanka. In order to improve quality of evidence in the court room, in order to deeply investigate a forensic or a legal issue, in order to cross examine, in order to make a rational judicial reasoning, in order for the lawyers and the parties to prepare for their cases, in order for the forensic research to advance in Sri Lanka, forensic research and new knowledge should reach the target audience afresh, fully and on time. Therefore, I strongly feel that the authorities should take steps to provide wider access to foreign journals and data bases where target parties can access full research articles, and then to promote publishing local research articles in Sri Lanka journal of forensic medicine science and law (or any other accessible local journal) so that it can readily reach the audience as it is available online free for anyone. It is also timely that authorities take steps to translate important and relevant new research findings and forensic knowledge to make them available to target audience as most of the court work is carried out in local languages.

I strongly believe that these approaches will not only improve quality of forensic evidence and court process of administration of justice, but also it will inform the general public and media about forensic breakthroughs and promote further research in the country. 